\title{
thebmj
}

Views \& Reviews Personal View

\section{Lessons from polyclinics in Central and Eastern Europe}

BMJ 2008; 337 doi: http://dx.doi.org/10.1136/bmj.a952 (Published 23 July 2008) Cite this as: BMJ 2008;337:a952

\author{
Bernd Rechel, honorary lecturer, Martin McKee, professor of European public health \\ ${ }^{1}$ London School of Hygiene and Tropical Medicine, London WC1E 7HT
}

Bernd.Rechel@Ishtm.ac.uk

For anyone from the former Soviet bloc-and there are quite a few doctors from the new member states of the European Union now working in the United Kingdom-the current discussion about the introduction of polyclinics in the English NHS must be utterly perplexing. Polyclinics were a centrepiece of the Soviet model of healthcare delivery, but many countries of Central and Eastern Europe have abandoned them over the past two decades in favour of a system of general practice that draws extensively on the British model. Advisers from the World Bank, the EU, and many bilateral donors agreed that the polyclinic had failed to deliver modern, integrated health care and saw general practices as the future. How can it be that England is now introducing a model that countries in Central and Eastern Europe were so recently encouraged to give up?

Although there is still considerable debate about what an English polyclinic might look like,1 they will share with their predecessors in Central and Eastern Europe the fundamental characteristic of uniting primary and specialist services in a single location. Soviet polyclinics provided outpatient care for populations in a specified geographical area (a so called medical district), employed general physicians (so called therapeutists) and various specialists, and were affiliated to a particular hospital. They were concentrated in urban areas, where they were the first point of contact with the health system and the main provider of primary health care. Children and adults attended separate facilities, staffed by different doctors. Care was of poor quality, with salaries low and facilities and equipment outdated. This model was replicated throughout the Soviet sphere of influence.2 3

Despite their limitations and a widely held view that the concept was outdated, polyclinics have proved remarkably resilient. Most countries of the former Soviet Union simply retained them, although some merged facilities for children and adults. In contrast, the former Soviet satellites in Central and Eastern Europe, now members of the EU, have mostly shifted provision of primary care to independent family doctors contracted with national health insurance funds or health insurance companies.4 Yet in many cases, the change has been limited. Many polyclinics remain open, although now sometimes in private hands or as not for profit enterprises. Some countries, such as Latvia, have simply redesignated them as "health centres," while in Bulgaria they are now called "diagnostic consultative centres." Often, independent doctors rent the rooms and equipment from the polyclinic where they had once been state 
employees. Furthermore, these general practitioners had often trained as specialists but have since had relatively short retraining courses in family medicine. This means that, in some cases, patients continue to see the same doctor in the same building as in the communist era.

The situation in Germany is of particular interest. After reunification in 1989, the polyclinics in the former East Germany were phased out, with the last one closing in 1995. Forced to become independent, many private doctors rented rooms in former polyclinics, sometimes investing their own funds to reequip them. While avoiding the term polyclinic, the German government reintroduced the concept under the name Medizinische Versorgungszentren (medical care centres) in 2004. As in England, the government hopes that this will improve cooperation between primary and secondary care, while reducing costs. 5

What lessons does this experience offer for England? One possibility is that the polyclinic model in Central and Eastern Europe is popular with patients and staff, bringing real benefits in bridging the gap between primary and specialist care that are difficult to replicate with a more dispersed network of general practitioners. This would argue in favour of the current English proposals. However, another is that health care manifests "path dependency," whereby the starting conditions act as a constraint on what can be achieved.6 From this perspective, it is difficult to change the way in which doctors have trained and worked for many years, and this may prevent the anticipated benefits of closer collaboration from being realised.

Either scenario is possible. However, change will incur substantial costs, both in the construction of new facilities and, much more importantly, in the organisational turmoil that will ensue. Furthermore, while greater provision of specialist services outside hospital may improve patient access, quality of care may decline, and costs may increase. 7 There are also local specificities. Many English hospitals are now funded through private finance initiative schemes, so even if specialist services move out, they may still have to be paid for.

When introducing an idea that has previously been tried elsewhere, it is important to draw on relevant experience. There is a strong case for piloting the proposed new model, to allow enough time to learn. Unfortunately, as the past two decades have shown, that is not how things work here.

\section{Notes}

Cite this as: BMJ 2008;337:a952

\section{References}

1. Finch R. When is a polyclinic not a polyclinic? BMJ2008;336:916-8.

2. Farmer RG, Sirotkin AY, Ziganshina LE, Greenberg HM.. The Russian health care system today: can American-Russian CME programs help? Cleve Clin J Med 2003;70:937-44.

3. Tragakes E, ed. Health care systems in transition: Russian Federation. Copenhagen: European Observatory on Health Systems and Policies, 2003.

4. Saltman RB, Rico A, Boerma W, eds. Primary care in the driver's seat? Organizational reform in European primary care. Maidenhead: Open University Press, 2006.

5. Hyde R. Controversy accompanies polyclinic revival in Germany. Lancet 2006;368:721-2.

6. Boas T. Conceptualizing continuity and change: the composite-standard model of path dependence. $J$ Theoret 
Politics2007;19:33-54.

7. Sibbald B, McDonald R, Roland M. Shifting care from hospitals to the community: a review of the evidence on quality and efficiency. J Health Services Res Policy2007;12:110-7. 